\title{
The Effect of Tamoxifen Administration and $\gamma$-Irradiation on Thyroid Hormones Levels in Rats Bearing Mammary Tumours
}

\author{
M. R Abdelgawad \\ Biological Applications Dept, Nuclear Research Centre (NRC), \\ Enshas, Egypt.
}

\begin{abstract}
B REAST CANCER is the most common malignancy among women in most developed and developing regions of the world, in female, tamoxifen acting as an oestrogen antagonist on the breast. Thyroid hormones can stimulate the proliferation in vitro of certain tumor cell lines. The aim of the present study is to evaluate the effect of tamoxifen and/ or irradiation treatment on thyroid hormones in rats' mammary tumours.

Forty-two female Sprague-Dawely rats randomly divided into seven groups' proliferation (6 rats each). Control group, normal rats supplemented with tamoxifen for 3 weeks, normal rats exposed to a single dose 3 Gy $\gamma$-rays, rats treated with Dimethylbenz (a) anthracene (DMBA) dissolved in corn oil (30ppm) sc and followed for 6 months until breast cancer occurrence, breast cancer bearing rats supplemented with tamoxifen for 3 weeks twice a day, breast cancer bearing rats exposed to a single dose $3 \mathrm{~Gy} \gamma$-rays, breast cancer bearing rats exposed to a single dose $3 \mathrm{~Gy} \gamma$-rays and supplemented with tamoxifen for 3 weeks twice a day. At the end of the experiment, mammary tumours and control rats were sacrificed after 3 weeks from different treatments and serum thyroid hormones and estradiol (E2) levels were assayed using commercial kits. Results show T4 and E2 levels not triiodothyronine (T3) were altered in different experimental groups. It could be concluded that $\gamma$-irradiation promote the expression of neoplastic potential by affecting both E2 and thyroid hormones and tamoxifen may alter the thyroid hormones.

Tamoxifen administration and $\gamma$-irradiation may have worth effects on thyroxin (T4) and E2 levels. It is recommended to further studies towards the bystander effect of $\gamma$-rays exposure and tamoxifen treatment on the tissue culture and molecular biology scale.
\end{abstract}

Key words: Tamoxifen, thyroid hormones, $\gamma$-rays, breast cancer. 
Breast cancer is the most common malignancy among women in most developed and developing regions of the world with nearly a million new cases each year. It accounts for nearly $21 \%$ of all cancers among women worldwide (Parkin et al., 1999). The distribution of breast cancer within developing countries shows a higher incidence of breast cancer in urban than in rural areas (Parkin et al., 2002). In Egypt, as in many other parts of the world, breast cancer is the most common type of cancer; it accounts for approximately $38 \%$ of reported malignancies among Egyptian women (Rennert, 2006).

Tamoxifen; [Z]-2-[4-(1,2-diphenyl-1-butenyl)-phenoxy]-N-N-dimethylethanamine is one of the most effective treatments for breast cancer. Standard practice is to select patients who are likely to respond to this therapy through the evaluation of oestrogen receptor (ER) and progesterone receptor (PR) in the primary tumour tissue (Ciocca and Elledge, 2000). Tamoxifen is a very effective anti-estrogenic compound widely used for treating women with breast cancer. Tamoxifen and chemotherapy provide similar benefit in advanced disease, although tamoxifen has relatively little toxicity (compared with chemotherapy agents) and is easier to administer, offering a better quality of life. Most actions of tamoxifen are attributed to its capacity to interact with ER. Tamoxifen belongs to the first generation of pharmaceutical agents now collectively called selective ER-modulators (SERMs). In women, this drug has tissue-specific effects, acting as an oestrogen antagonist on the breast, and as an oestrogen agonist on bone, lipid metabolism (increasing high-density lipoprotein cholesterol and decreasing low-density lipoprotein cholesterol), and the endometrium (Fitzpatrick, 1999).

Hamada et al. (2007) reported several mediating mechanisms have been proposed. These involve gap junction-mediated intercellular communication (GJIC), secreted soluble factors, oxidative metabolism, plasma membranebound lipid rafts, and calcium fluxes. However, The potential benefit of bystander effects to cancer radiotherapy as the mechanisms of the bystander effects involve paracrine processes in addition to GJIC, the elucidation of the early-and late-arising effects in surrounding and distant normal tissues/organs have not cleared so far and awaits further extensive studies. Thyroid hormones act on almost all organs throughout the body and regulate the basal metabolism of the organism (Guyton, 1991). Thyroid hormone can also stimulate the Egypt. J. Rad. Sci. Applic., Vol. 26, No. 1-2 (2013) 
proliferation in vitro of certain tumour cell lines (Davis et al., 2005).

The aim of the present study is to evaluate the effect of tamoxifen and/ or $\gamma$-irradiation treatments on thyroid hormones and E2 levels in breast cancer bearing rats.

\section{Materials and methods}

\section{Animals}

Forty-two female Sprague-Dawely rats obtained from Naval American Research Unit (NAMRU) housed and reared in Animal Research Unit, Faculty of Science, Mansoura University, weighing 190-210g were housed in plastic cages. Animals were fed on a standard rat chow with tap water ad libitum, randomly divided into seven groups (each composed of six rats in cage) and mentioned under standard conditions $\left(22 \pm 3^{\circ} \mathrm{C}\right.$ and $40-70 \%$ relative humidity) as follow. 1.Control group. 2.Rat group supplemented orally with tamoxifen $(10 \mathrm{mg} / \mathrm{Kg}$ ) for 3 weeks twice a day (tamoxifen tablets of $10 \mathrm{mg}$ was suspended in $10 \mathrm{ml}$ distilled water). 3.Irradiated rats exposed to a single dose (3Gy/ min) of $\alpha$-rays $\left({ }^{60} \mathrm{Cobalt}\right)$ at the Nuclear Medicine Centre for Diagnosis and Therapy, Mansoura University, Egypt. 4.Rats treated with DMBA dissolved in corn oil (30ppm) sc and followed for 6 months until breast cancer occurrence. 5.Breast cancer bearing rats supplemented with tamoxifen $(10 \mathrm{mg} / \mathrm{kg}$ ) for 3 weeks twice a day, as mentioned above in group 2. 6.Breast cancer bearing rats exposed to a single dose $3 \mathrm{~Gy}(3 \mathrm{~Gy} / \mathrm{min})$ from $\alpha$-rays $\left({ }^{60} \mathrm{Cobalt}\right)$ as in group 3. 7.Breast cancer bearing rats exposed to a single dose $3 \mathrm{~Gy}(3 \mathrm{~Gy} / \mathrm{min})$ from $\gamma$-rays $\left({ }^{60}\right.$ Cobalt) and supplemented with tamoxifen $(10 \mathrm{mg} / \mathrm{kg})$ for 3 weeks twice a day as mentioned above in groups $2 \& 3$.

\section{Assay of the serum oestrogen and thyroid hormones samples}

Vaginal smears were taken and examined every day during the last month; only rats with regular 4-day oestrous cycles were used, at the end of the experiment.

Rats from each group were anesthetized by chloroform and killed after blood collection for suitable assays by cardiac puncture using stainless steel needle in polypropylene plastic tubes without additives. After clotting at room temperature, the tubes were centrifuged at $1500 \mathrm{xg}$ for $10 \mathrm{~min}$ and the serum was 
collected. The serum (T3\&T4) and E2 concentrations were assayed by radioimmunoassay (RIA) kits; Immunotech, IM 1699, Beckman Coulter Company and Siemen Medical Solutions Diagnostics, TKE21-2125, USA, respectively.

\section{Histopathological examination}

The rats were palpated regularly for mammary tumours starting from 2 months after treatment with DMBA. The rats were killed at the end of the experiment, after different treatments when rats bearing mammary tumours became moribund. The mammary tumours were removed, cut to small pieces and fixed immediately in 10\% phosphate-buffered formalin ( $\mathrm{pH} 7.2$ ), embedded in paraffin. Paraffin sections ( $4 \mu \mathrm{m}$ in thickness) were prepared and stained with haematoxylin and eosin (H\&E) for histo-pathological examination, using the criteria and classification of mammary tumours as outlined by Young and Hallowes (1973) and Russo et al. (1990).

\section{Statistical analysis}

The statistical analysis was computed using Instate program and the data characterized by their means and standard Error (mean \pm S.E.) was done by $t$-test, ANOVA and Student-Neuman-Keuls for comparing all pairs columns, $P$-value $<0.05$ was considered to be statistical significant, and r-value was calculated by spearman correlation coefficient.

\section{Results}

No loss of rats was reported during initiation and progression of mammary tumours and after different treatments. In addition, there was no difference in survival during different treatments. Histo-pathological examination of control and mammary tumours bearing rats illustrated in Fig. $1^{\text {a\&b }}$.

The level of T3 was significantly higher $(P<0.05)$ in normal rats postIrradiated group in comparison with other groups. T3 level does not significantly differentiate between control group and treated groups with tamoxifen. Breast cancer and tamoxifen plus $\gamma$-irradiation; tamoxifen group versus compound breast cancer treatment with tamoxifen and $\gamma$-irradiation. In the same time, $\mathrm{T} 3$ level has non-significant difference in comparing breast cancer group and treated breast cancer with tamoxifen and $\gamma$-irradiation, Table 1.

Egypt. J. Rad. Sci. Applic., Vol. 26, No. 1-2 (2013) 


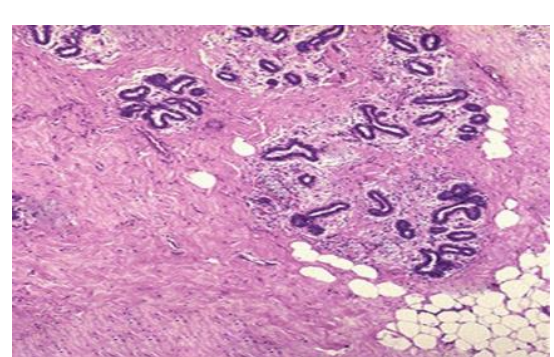

(a) Control (H\&E 200x)

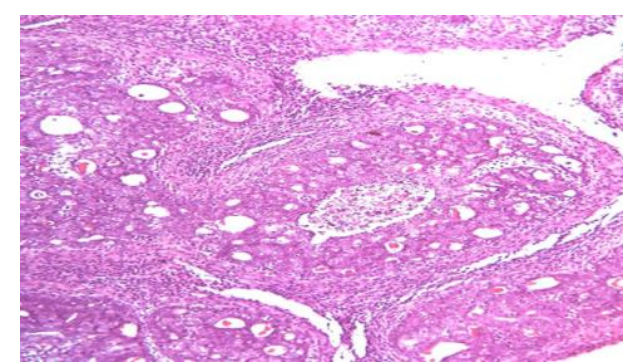

(b) Mammary gland tumour (H\&E 200x)

Fig. 1. Control and mammary gland tumour.

TABLE 1. Serum T3 and T4 levels in female Sprague-Dawley rats in different groups.

\begin{tabular}{|c|c|c|}
\hline Item & T3 $(\mathbf{n m o l e} / \mathbf{m l})$ & $\mathbf{T 4}(\mathbf{p m o l e} / \mathbf{m l})$ \\
\hline Control & $0.14^{\mathrm{c}} \pm 0.004$ & $209.07^{\mathrm{a}} \pm 1.74$ \\
\hline Tam & $0.14^{\mathrm{c}} \pm 0.01$ & $214.00^{\mathrm{a}} \pm 3.56$ \\
\hline IR & $0.24^{\mathrm{a}} \pm 0.01$ & $121.17^{\mathrm{c}} \pm 2.03$ \\
\hline BC & $0.14^{\mathrm{c}} \pm 0.01$ & $76.45^{\mathrm{d}} \pm 3.09$ \\
\hline BC+ Tam & $0.20^{\mathrm{b}} \pm 0.01$ & $143.0^{\mathrm{b}} \pm 8.15$ \\
\hline BC+ IR & $0.10^{\mathrm{d}} \pm 0.01$ & $38.60^{\mathrm{e}} \pm 3.09$ \\
\hline BC+ Tam+ IR & $0.15^{\mathrm{c}} \pm 0.01$ & $69.90^{\mathrm{c}} \pm 4.47$ \\
\hline
\end{tabular}

Tam: Tamoxifen. IR: Irradiation. BC: Breast cancer.

Values with different letters considered significant $(P<0.05) . \quad \mathrm{n}=6$ rats.

T4 hormone level was significantly higher $(P<0.05)$ in both control group and rats treated with tamoxifen than other studied groups. T4 hormone level does not significantly discriminate between control group versus rats treated with tamoxifen. T4 level has non significant difference in comparing between breast cancer group and treated breast cancer with tamoxifen and irradiation, Table 1.

Table 2. Serum concentration of E2, and T3/ T4 and E/ (T3/ T4) in female SpragueDawley rats in different groups.

\begin{tabular}{|c|c|c|c|}
\hline Item & $\mathbf{( T 3 / T 4}_{*} \mathbf{1 0}^{\mathbf{6}}(\mathrm{nmole} / \mathrm{ml})$ & $\mathbf{E}(\mathrm{pg} / \mathrm{ml})$ & $\mathbf{E} / \mathbf{( T 3 / ~ T 4}) * \mathbf{1 0}^{-\mathbf{3}}$ \\
\hline Control & $0.66^{\mathrm{e}} \pm 0.02$ & $6.25^{\mathrm{b}} \pm 0.13$ & $9.58^{\mathrm{b}} \pm 0.45$ \\
\hline Tam & $0.65^{\mathrm{e}} \pm 0.03$ & $6.87^{\mathrm{a}} \pm 0.16$ & $10.71^{\mathrm{a}} \pm 0.59$ \\
\hline IR & $2.03^{\mathrm{c}} \pm 0.13$ & $6.88^{\mathrm{a}} \pm 0.15$ & $3.45^{\mathrm{c}, \mathrm{d}} \pm 0.19$ \\
\hline BC & $1.80^{\mathrm{c}} \pm 0.10$ & $4.32^{\mathrm{d}} \pm 0.19$ & $2.44^{\mathrm{d}, \mathrm{e}} \pm 0.18$ \\
\hline BC+ Tam & $1.40^{\mathrm{d}} \pm 0.13$ & $5.33^{\mathrm{c}} \pm 0.16$ & $4.01^{\mathrm{c}} \pm 0.45$ \\
\hline BC+ IR & $2.73^{\mathrm{a}} \pm 0.16$ & $4.08^{\mathrm{d}} \pm 0.16$ & $1.53^{\mathrm{e}} \pm 0.14$ \\
\hline BC+ Tam+ IR & $2.09^{\mathrm{b}} \pm 0.14$ & $5.02^{\mathrm{c}} \pm 0.28$ & $2.27^{\mathrm{d}, \mathrm{e}} \pm 0.31$ \\
\hline
\end{tabular}

Legends in Table 1.

T3/ T4 ratio was significantly $(P<0.05)$ higher in post-irradiated breast cancer group and post-irradiated breast cancer treated with tamoxifen group and 
normal rats post-irradiated group than other studied groups. There is nonsignificance of $\mathrm{T} 3 / \mathrm{T} 4$ ratio in comparing with control group with rats treated with tamoxifen; post-irradiated breast cancer rats treated with tamoxifen with breast cancer group and finally, non-significance difference in the value of T3/ T4 between post-irradiated group and breast cancer group (Table 2). Serum E2 level was significantly $(P<0.05)$ increased in normal rats post-irradiation and normal rats treated with tamoxifen groups in comparing with control, breast cancer and breast cancer treated with tamoxifen and tamoxifen post-irradiated breast cancer groups. The level of serum E2 hormone remains at the same level $(\sim 6.88 \pm 0.15$ and $6.87 \pm 0.16 \mathrm{pg} / \mathrm{ml})$ in rats treated with tamoxifen and postirradiation groups, respectively (Table 2). The serum E2 hormone has nonsignificant difference in comparing between breast cancer group and postirradiated breast cancer; and treated breast cancer with tamoxifen with breast cancer treated tamoxifen and post-irradiation, Table 2.

TABLE 3. The correlation of $T 3$ level in different studied groups.

\begin{tabular}{|c|c|c|c|c|c|c|}
\hline Item & C & Tam & IR & Bc & Bc \pm Tam & Bc \pm IR \\
\hline Tam & -0.546 & 1 & & & & \\
\hline IR & -0.203 & 0.317 & 1 & & & \\
\hline BC & 0.379 & -0.929 & -0.215 & 1 & & \\
\hline BC+ Tam & 0.564 & -0.197 & -0.227 & 0.076 & 1 & \\
\hline BC+ IR & 0.220 & -0.155 & 0.631 & 0.166 & 0.530 & 1 \\
\hline BC+ Tam+ IR & -0.188 & 0.021 & -0.034 & -0.118 & 0.619 & 0.522 \\
\hline
\end{tabular}

Legends in Table 1.

The value of E2/ (T3/ T4) ratio was significantly higher in control and rats treated with tamoxifen groups $(9.28 \pm 0.45$ and $10.71 \pm 0.59$, respectively) than other groups. The E2/ (T3/ T4) ratio has non-significant diagnostic value in differentiating between breast cancer post-irradiated rats treated with tamoxifen and breast cancer; post-irradiated breast cancer and normal rats post-irradiated groups. At the same time, E2/ (T3/ T4) ratio has non-significant between breast cancer group and post-irradiated and post-irradiated breast cancer groups and also, post-irradiation group with breast cancer rats treated with tamoxifen (Table 2). There is a strong negative correlation of serum T3 level between normal rats treated with tamoxifen group and breast cancer group; a positive correlation between normal irradiated rats and irradiated breast cancer; irradiated breast cancer group treated with tamoxifen and breast cancer group treated with tamoxifen, Table 3.

Egypt. J. Rad. Sci. Applic., Vol. 26, No. 1-2 (2013) 
TABLE 4. The correlation of $\mathrm{T} 4$ level in different studied groups.

\begin{tabular}{|c|c|c|c|c|c|c|}
\hline Item & C & Tam & IR & Bc & Bc \pm Tam & Bc \pm IR \\
\hline Tam & 0.230 & 1 & & & & \\
\hline IR & -0.414 & 0.416 & 1 & & & \\
\hline BC & -0.817 & -0.314 & -0.061 & 1 & & \\
\hline BC+ Tam & 0.082 & 0.228 & -0.316 & -0.047 & 1 & \\
\hline BC+ IR & -0.112 & -0.009 & -0.602 & 0.575 & 0.097 & 1 \\
\hline BC+ Tam+ IR & 0.728 & 0.309 & -0.660 & -0.461 & 0.626 & 0.323 \\
\hline
\end{tabular}

Legends in Table 1.

There is a strong negative correlation of serum $\mathrm{T} 4$ level between control group and breast cancer group; in the same time, there is a strong positive correlation of serum $\mathrm{T} 4$ between irradiated breast cancer group treated with tamoxifen and either control and breast cancer group treated with tamoxifen, Table (4).

TABLE 5. The correlation of T3/ T4 ratio in different studied groups.

\begin{tabular}{|c|c|c|c|c|c|c|}
\hline Item & C & Tam & IR & Bc & Bc \pm Tam & Bc \pm IR \\
\hline Tam & -0.269 & 1 & & & & \\
\hline IR & -0.131 & 0.396 & 1 & & & \\
\hline BC & -0.479 & -0.542 & -0.074 & 1 & & \\
\hline BC+ Tam & 0.668 & -0.488 & -0.400 & -0.051 & 1 & \\
\hline BC+ IR & -0.653 & 0.017 & 0.449 & 0.328 & -0.826 & 1 \\
\hline BC+ Tam+ IR & 0.383 & -0.65 & -0.683 & -0.093 & 0.278 & -0.072 \\
\hline
\end{tabular}

Legends in Table 1.

There is a strong negative correlation of $\mathrm{T} 3 / \mathrm{T} 4$ ratio between irradiated breast cancer group and either control or breast cancer treated with tamoxifen group; in the same time, there is a positive correlation between control group and breast cancer treated with tamoxifen, Table 5 .

TABLE 6. The correlation of E2/ (T3/T4) ratio in different studied groups.

\begin{tabular}{|c|c|c|c|c|c|c|}
\hline Item & C & Tam & IR & Bc & $\mathbf{B c} \pm$ Tam & Bc \pm IR \\
\hline Tam & -0.650 & 1 & & & & \\
\hline IR & -0.328 & 0.479 & 1 & & & \\
\hline BC & -0.585 & 0.277 & 0.469 & 1 & & \\
\hline BC+ Tam & 0.655 & -0.726 & -0.367 & -0.366 & 1 & \\
\hline BC+ IR & -0.241 & -0.163 & 0.440 & 0.278 & -0.395 & 1 \\
\hline BC+ Tam+ IR & 0.391 & -0.850 & -0.705 & -0.020 & 0.534 & 0.003 \\
\hline
\end{tabular}

Legends in Table 1. 
There is a strong negative correlation of [E2/ (T3/ T4)] ratio between normal rats treated with tamoxifen and breast cancer group treated with tamoxifen group, on the other hand, there is a positive correlation between control group and breast cancer treated with tamoxifen, Table 6 .

\section{Discussion}

An alternative theory considers that carcinogenesis is a process akin to development gone awry (Sonnenschein and Soto, 1999). The Tissue Organization Field Theory proposes that carcinogens alter stromal-epithelial interactions and that proliferation is the default state of all cells (Sonnenschein and Soto, 2000). SERMs are a group of anti-oestrogens that possess agonistic activity on bone metabolism, and lipids and lipoproteins but antagonistic action on the breast and endometrium (Spencer et al., 1999).

The expected anti-proliferative effects of tamoxifen on mammary epithelium, tamoxifen treatment was found to induce pleiotropic changes in the mammary microenvironment (Hattar et al., 2009). This response of the mammary stroma to tamoxifen treatment provides further evidence for the hypothesis that dynamic and reciprocal interactions occur between epithelium and stroma and that these interactions dictate epithelial cell function (Spencer et al., 2007).

Ionizing radiation is a complete carcinogen, able both to initiate and promote neoplastic progression (Fry et al., 1982) and is a known carcinogen of human breast (Mattsson et al., 1993) and rodent mammary glands (Gould et al., 1991).

Smith et al. (2012) found that treatment with brachytherapy compared with whole body irradiation (WBI) was associated with worse long-term breast preservation and increased complications but no difference in survival.

In the present study, T3 level was significantly $(P<0.05)$ decreased in breast cancer post-irradiation compared with other studied groups and especially with $\gamma$-irradiated breast cancer treated with tamoxifen group. While, serum T4 level was significantly decline in comparison all treated group with control group. T3/T4 ratio was increased significantly in all studied groups compared with control group and normal rats treated with tamoxifen only.

Egypt. J. Rad. Sci. Applic., Vol. 26, No. 1-2 (2013) 
Evidence that thyroid hormone can act primarily outside the cell nucleus has come from studies of mitochondrial responses to $\mathrm{T}_{3}$ (Silvestri et al., 2005) or $\mathrm{T} 2$ (Wrutniak-Cabello et al., 2001), from rapid onset effects of the hormone at the cell membrane (Incerpi et al., 1999) and from actions on cytoplasmic proteins (Vie et al., 1997).

Serum E2 level was significantly lower in breast cancer group and postirradiated breast cancer, with insignificant difference in-between. E2 is considered to be a potent mitogen for the normal mammary gland, whereas thyroid hormones appear to stimulate lobular development, contributing to the differentiation of normal breast tissue (Neville et al., 2002). The biological activity of thyroid hormones and E2 is manifested only in cell expressing TR and ER, respectively that belong to the nuclear receptor superfamily. These receptors share a common mechanism on action whereby hormone-receptor complexes bound to cis acting DNA elements enhance or repress transcription of target genes (Jensen et al., 2001).

The relationship between breast cancer and TH are controversial. Even though many studies have shown that thyroid diseases are common in women with breast cancer, other reports have not confirmed this association (Turken et al., 2003) and it has also been suggested that free-T3 plays an important role in the physiology of fibrocystic breast disease (Martinez et al., 1995). Consistent with the proposal that TH act on the breast, TR have been described in breast cancer (Silva et al., 2002). The more active form of TH; T3, significantly enhance E2 growth stimulation of a number of human breast carcinoma cell lines (Shao et al., 1995). In T47D breast cancer cells, E2 and T3 similarly regulate cell cycle progression and proliferation raising the p53 level and causing hyperphosphorylation of retinoblastoma gene product (pRb) (Dinda et al., 2002).

Dinda et al. (2002) postulated that the estrogen-like effects of T3 were mediated by TR interaction with ER response element. Therefore, another possibility is that $\mathrm{T} 3$ bound to the $\mathrm{T} 3$ receptor, independently of ER, stimulates ER response element function, promoting transcription of target genes that lead to cellular proliferation.

The recent description of a plasma membrane receptor for $\mathrm{TH}$ on integrin $\alpha \mathrm{V} \beta 3$ (Mousa et al., 2006) has provided some insight into effects of the 
hormone on membrane ion pumps, such as the $\mathrm{Na}^{+} / \mathrm{H}^{+}$antiporter (D'Arezzo et al., 2004) and has led to the description of interfaces between the membrane TH-receptor and nuclear events that underlie important cellular or tissue processes, such as angiogenesis (Mousa et al., 2005) and proliferation of certain tumour cells (Tang et al., 2004).

Oestrogens are produced primarily by developing follicles in the ovaries, the corpus luteum, and the placenta. Follicle-stimulating hormone (FSH) and luteinizing hormone ( $\mathrm{LH})$ stimulate the production of oestrogen in the ovaries. Some oestrogens are also produced in smaller amounts by other tissues such as the liver, adrenal glands, and the breasts. These secondary sources of oestrogens are especially important in postmenopausal women (Kulendran et al., 2009).

In females, synthesis of estrogens starts in theca interna cells in the ovary by the synthesis of androstenedione from cholesterol. Androstenedione is a substance of moderate androgenic activity. This compound crosses the basal membrane into the surrounding granulosa cells, where it is converted to oestrone or E2, either immediately or through testosterone. The conversion of testosterone to E2, and of androstenedione to oestrone is catalysed by the enzyme aromatase. E2 levels vary through the menstrual cycle, with levels highest just before ovulation (Simpson and Davis, 2001).

In a previous study, El-kot and Abdelgawad (2009) suggested that sex hormones have a role in late stages in breast carcinogenesis. E2, which is the main form of oestrogen, has affects the different stage of mammary gland carcinogenesis. A meta-analysis of nine prospective studies observed a twofold increase in breast cancer risk in women with E2 levels in the highest, relative to the lowest, quintile, with similar associations noted for oestrone, oestrone sulphate and testosterone (Key et al., 2002). In the present study, serum E2 was significantly lower in breast cancer group than control. Whereby, Farhat et al. (2013) reported that serum E2 was significantly higher in breast cancer women than control.

The value of E2/ (T3/ T4) ratio was significantly lower in post-irradiated breast cancer, breast cancer post-irradiated rats treated with tamoxifen and breast cancer groups compared with other studied groups including control, normal rats treated with tamoxifen, post-irradiated rats and breast cancer Egypt. J. Rad. Sci. Applic., Vol. 26, No. 1-2 (2013) 
treated with tamoxifen groups. Saraiva et al. (2005) showed that postmenopausal breast cancer patients have a significantly increased TH/ E2 ratio, suggesting a possible tumour growth-promoting effect caused by this misbalance. TH acts as the body's thermostat, regulating the rate at which virtually all biochemical reactions occur in the body. Inadequate conversion of T4 to T3 by the liver may lead energy-depleting hypothyroidism, leading to chronic fatigue, weight gain and poor memory (Daher et al., 2009).

It could be concluded that irradiation-induced changes in the expression of neoplastic potential by affecting both E2 and TH and tamoxifen may alter the TH. Irradiation and tamoxifen administration may have worth effects on T4 and E2 levels and it is recommended to further studies towards the bystander effect of radiation and tamoxifen on the tissue culture and molecular biology scale.

\section{References}

Ciocca, D. R. and Elledge, R. (2000) Molecular markers for predicting response to tamoxifen in breast cancer patients. Endocrine, 13, 1.

D'Arezzo, S., Incerpi, S., Davis, F. B., Acconia, F., Marino, M., Farias, R. N. and Davis, P. J. (2004) Rapid nongenomic effects of 3,5,3'-triiodo-L-thyronine on the intracellular $\mathrm{pH}$ of L-6 myoblasts are mediated by intracellular calcium mobilization and kinase pathways. Endocrinology, 145, 5694.

Daher, R., Yazbeck, T., Jaoude, J. b. and Abboud, B. (2009) Review consequences of dysthyroidism on the digestive tract and viscera. World J. Gastroenterol., 21, 2834.

Davis, P. J., Davis, F. B., Cody, V. (2005) Membrane receptors mediating thyroid hormone action. Trends Endocrinol. Metab., 16, 429.

Dinda, S., Sanchez, A. and Moudgil, V. (2002) Estrogen-like effects of thyroid hormone on the regulation of tumor suppressor proteins, p53 and retinoblastoma, in breast cancer cells. Oncogene, 21, 761.

El-kot, A. and Abdelgawad, M. R. (2009) The Protective effect of Spirulina platensis against mammary tumors induction by Dimethylbenz (A) Anthracene in sprague-dawley female rats. Isotop. \& Rad Res, 41, 787.

Farhat, G. N., Parimi, N., Chlebowski, R. T., Manson, J. E., Anderson G., Huang, A. J., Vittinghoff, E., Lee, J. S., LaCroix, A. Z., Cauley, J. A., Jackson, R., Grady, D, Lane, D. S., Phillips, L., Simon, M. S., Cummings, S. R. (2013) Sex hormone levels and risk of breast cancer with estrogen plus progestin. J. Natl. Cancer Inst., 105, 1496.

Fitzpatrick, L. A. (1999) Mayo clin. selective estrogen receptor modulators and phytoestrogens: new therapies for the postmenopausal women. Proc. 74, 601.

Egypt. J. Rad. Sci. Applic., Vol. 26, No. 1-2 (2013) 
Fry, R. J. M., Ley, R. D., Grube, D. and Staffeldt, E. (1982) Studies on the multistage nature of radiation carcinogenesis. Carcinogen, 7, 155.

Gould, M. N., Clifton, K. H., Damiya, K., Wang, B., and Zhang, R. (1991) Quantitative and molecular comparison of initiation frequency of mammary carcinogenesis by radiation and chemical carcinogens. Radiat. Environ. Biophys., 30, 221.

Guyton, A. (1991) The thyroid metabolic hormones. In: Medical Physiology Textbook, editor. $8^{\text {th }}$ edition. Philadelphia: Saunders, pp. 831-841.

Hamada, N., Matsumoto, H., Hara, T. and Kobayashi, Y. (2007) Intercellular and intracellular signaling pathways mediating ionizing radiation-induced bystander effects. J. Radiat. Res., $\mathbf{4 8}, 87$.

Hattar, R., Maller, O., McDaniel, S., Hansen, K. C., Hedman, K. J. (2009) Tamoxifen induces pleiotrophic changes in mammary stroma resulting in extracellular matrix that suppresses transformed phenotypes. Breast Cancer Res., 11, 1.

Incerpi, S., Luly, P., De Vito, P. and Farias, R. N. (1999) Short-term effects of thyroid hormones on the $\mathrm{Na} / \mathrm{H}$ antiport in L-6 myoblasts: high molecular specificity for 3,5,3'-triiodo-L-thyronine. Endocrinology, 140, 683.

Jensen, E. V., Cheng, G., Saji, S., Makela, S., Noorden, S. V., Wahlstrom, T., Warner, M., Coombes, R. C. and Gustafsson, J. (2001) Estrogen receptors and proliferation markers in primary and recurrent breast cancer. Proc. Nat. Acad. Sci., 98, 15197.

Key, T., Appleby, P., Barnes, I. and Reeves, G. (2002) Endogenous sex hormones and breast cancer in postmenopausal women: reanalysis of nine prospective studies. J. Natl. Cancer Inst., 94, 606.

Kulendran, M., Salhab, M. and Mokbel, K. (2009) Oestrogen-synthetising enzymes and breast cancer. Anticancer Res., 29, 1095.

Martinez, L., Castilla, J. A., Gil, T., Molina, J., Alarcon, J. L., Marcos, C. and Herruzo, A. (1995) Thyroid hormones in fibrocystic breast disease. Eur. J. Endocrinol., 6, 673.

Mattsson, A., Ruden, B. I., Wilking, N. and Rutqvist, L. E. (1993) Radiation-induced breast cancer: long-term follow-up of radiation therapy for benign breast disease. J. Natl. Cancer Inst., 85, 1679.

Mousa, S. A., O'Connor, L. J., Bergh, J. J., Davis, F. B., Scanlan, T. S. and Davis, P. J. (2005) The proangiogenic action of thyroid hormone analogue GC-1 is initiated at an integrin. J. Cardiovasc. Pharmacol., 46, 356.

Mousa, S. A., O'Connor, L., Davis, F. B. and Davis, P. J. (2006) Proangiogenesis action of the thyroid hormone analog 3,5-diiodothyropropionic acid (DITPA) is initiated at the cell surface and is integrin-mediated. Endocrinology, 147, 1602.

Egypt. J. Rad. Sci. Applic., Vol. 26, No. 1-2 (2013) 
Neville, M. C., McFadden, T. B. and Forsyth, I. (2002) Hormonal regulation of mammary differentiation and milk secretion. J. Mammary Gland Biol. Neoplasia, 1, 49.

Parkin, D. M., Pisani. P. and Ferlay, J. (1999) Estimates of the worldwide incidence of 5 major cancers in 1990. Int. J. Cancer, 80, 827.

Parkin, D. M., Whelan, S. L., Ferlay, J., Teppo, L. and Thomas, D. B. (ed) (2002) Cancer incidence in five continents, Vol. VIII, IARC Sc. Publication, No.155, Lyon.

Rennert, G. (2006) Breast cancer. In: Freedman L, Edwards, B., Ries, L., Young, J. (eds), Cancer incidence in four member countries (Cyprus, Egypt, Israel, and Jordan) of the Middle East cancer consortium (MECC) compared with US SEER. National Cancer Institute (NIH), Bethesda; Pub. No. 06-5873.

Russo, J., Russo, I. H., Rogers, A. E., VAN Zwieten, M. J., Gusterson, B. (1990) Tumors of mammary gland. In: Turusov V, Mohr U(ed). Pathology of tumours in laboratory animals. Vol. 1, IARC Scientific Publications, Lyon, pp. 47-78.

Saraiva, P. P., Figueiredo, N. B., Padovani, C. R., Brentani, M. M. and Nogueira, C. R. (2005) Profile of thyroid hormones in breast cancer patients. Braz. J. Med. Biol. Res, 38, 761.

Shao, Z., Sheikh, M. S., Rishi, A. H., Dawson, M. I., Li, X., Wilber, J. F., Feng, P. and Fontana, J. A. (1995) Thyroid hormone enhancement of estradiol stimulation of breast carcinoma proliferation. Exp. Cell Res., 218, 1.

Silva, J. M., Dominguez, G., Gonzalez-Sancho, J. M., Garcia, J. M., Silva, J., Garcia-Andrade, C., Navarro, A., Munoz, A. and Bonilla, F. (2002) Expression of thyroid hormone receptor/erbA genes is altered in human breast cancer. Oncogene, 21, 4307.

Silvestri, E., Schiavo, L., Lombardi, A. and Goglia, F. (2005) Thyroid hormones as molecular determinants of thermogenesis. Acta Physiol. Scand., 184, 265.

Simpson, E. R. and Davis, R. (2001) Minireview: aromatase and the regulation of estrogen biosynthesis-some new perspectives. Endocrinology, 142, 4589.

Smith, G. L., Xu, Y., Buchholz, T. A., Giordano, S. H., Jiang, J., Shih, Y. T. and Smith, B. D. (2012) Association between treatment with brachytherapy vs. whole-breast irradiation and subsequent mastectomy, complications, and survival among older women with invasive breast cancer. JAMA, 307, 1827.

Sonnenschein, C. and Soto, A. M. (1999) The Society of Cells: Cancer and Control of Cell Proliferation. New York: Springer-Verlag, p. 749.

Sonnenschein, C. and Soto, A. M. (2000) The somatic mutation theory of carcinogenesis: Why it should be dropped and replaced. Mol. Carcinog., 29, 1.

Spencer, C. P., Morris, E. P. and Rymer, J. M. (1999) Selective estrogen receptor 
modulators: Women's Panaceas for the next millennium? Am. J. Obstet. Gynecol., 180, 763.

Spencer, V. A., Xu, R. and Bissell, M. J. (2007) Extracellular matrix, nuclear and chromatin structure, and gene expression in normal tissues and malignant tumors: a work in progress. Adv. Cancer Res., 97, 275.

Tang, H. Y., Lin, H. Y., Zhang, S., Davis, F. B. and Davis, P. J. (2004) Thyroid hormone causes mitogen-activated protein kinase-dependent phosphorylation of the nuclear estrogen receptor. Endocrinology, 145, 3265.

Turken, O., NarIn, Y., DemIrbas, S., Onde, M. E., Sayan, O., Kandemir, E. G., Yaylac, I. M. and Ozturk, A. (2003) Breast cancer in association with thyroid disorders. Breast Cancer Res., 5, R110.

Vie, M. P., Evrfard, C., Osty, J., Breton-Gilet, A., Blanchet, P., Pomerance, M., Rouget, P., Francon, J. and Blondeau, J. P. (1997) Purification, molecular cloning, and functional expression of the human nicotinamide-adenine dinucleotide phosphate-regulated thyroid hormone-binding protein. Mol. Endocrinol., 11, 1728.

Wrutniak-Cabello, C., Casas, F. and Cabello, G. (2001) Thyroid hormone action in mitochondria. J. Mol. Endocrinol., 26, 67.

Young, S. and Hallowes, R. C. (1973) Tumours of the Mammary Gland. In: Pathology of Tumours in Laboratory Animals: Tumours of the rat, ed. Turusov VS, Int. Agency for Res. on Cancer, Switzerland, vol. 1, part 1.

(Received: 30/09/2013;

accepted: 31/12/2013)

Egypt. J. Rad. Sci. Applic., Vol. 26, No. 1-2 (2013) 
THE EFFECT OF TAMOXIFEN ADMINISTRATION AND $\gamma$-IRRADIATION... 129

تأثير المعاملة بالتاموكسفين و التشعيع الجـامى على مستويات

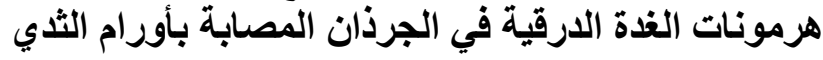

محمد رمضان عبد الجواد

قسم التطبيقات البيولوجية ، مركز البحوث النووية ، اشناص ، مصر.

\begin{abstract}
يعد سـرطان الثدي من أكثر الأورام انتشـار ا في كـلا مـن دول العـالم

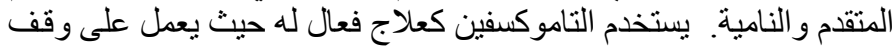

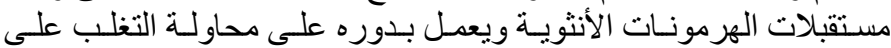

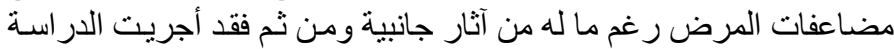

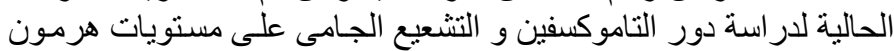

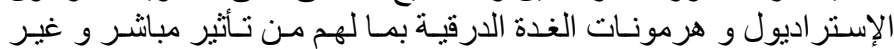

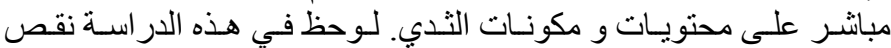

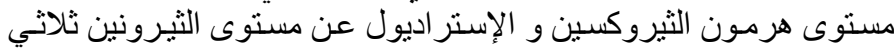

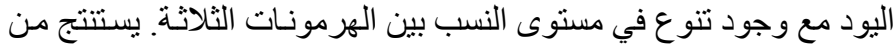

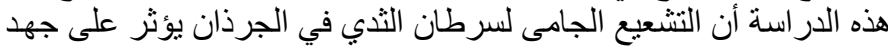

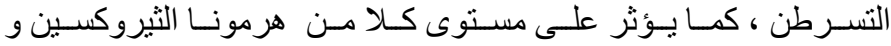

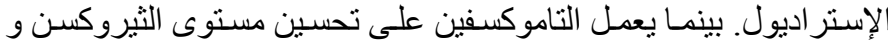

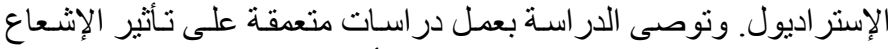

المار و التاموكسفين على مستوى زر اعة الأنسجة و البيولوجيا الجزيئية.
\end{abstract}

Egypt. J. Rad. Sci. Applic., Vol. 26, No. 1-2 (2013) 